\title{
Influence of Smoking Habits on the GA/HbA1c Ratio in Patients with Type 1 Diabetes Mellitus
}

\author{
Kazuhiko Kotani ${ }^{a, b}$ Naoki Sakane ${ }^{b}$ Michiaki Miyamoto ${ }^{a} \quad K^{2}$ azunori Yamada ${ }^{b}$ \\ Nobuyuki Taniguchia \\ a Department of Clinical Laboratory Medicine, Jichi Medical University, Shimotsuke, and ${ }^{b}$ National Hospital \\ Organization, Kyoto Medical Center, Kyoto, Japan
}

\section{Key Words}

Body mass index $\cdot$ Glycated albumin $\cdot$ Glycated

hemoglobin

\begin{abstract}
Objective: To assess the influence of smoking on glycated albumin (GA) to hemoglobin $\mathrm{A} 1 \mathrm{c}(\mathrm{HbA} 1 \mathrm{c})$ ratio among type 1 diabetes mellitus (T1DM) patients. Subjects and Methods: Eighty-one T1DM patients (49 females, 32 males, mean age $48 \pm 18$ years) were recruited, and data concerning GA/ $\mathrm{HbA1c}$ ratio and smoking were collected. Results: The median levels of GA and $\mathrm{HbA} 1 \mathrm{c}$ were 23.3 and $7.4 \%$, respectively. Independent of age, sex and/or body mass index, the GA/ $\mathrm{HbA} 1 \mathrm{c}$ ratio in smokers was significantly lower than that in nonsmokers (3.0 vs. 3.3, p<0.05). Conclusion: The data suggest that smoking might affect the $\mathrm{GA} / \mathrm{HbA} 1 \mathrm{c}$ ratio among T1DM patients.

Copyright $\odot 2010$ S. Karger AG, Basel
\end{abstract}

\section{Introduction}

For monitoring glycemic control in diabetes mellitus (DM), serum glycated albumin (GA, representing glycemic control over the preceding 2-3 weeks) has recently been used in addition to glycated hemoglobin (HbAlc, control over the preceding 2-3 months) [1]. GA has been shown to be a better measure than HbAlc in patients with short-term glycemic variations [1]. The GA/HbAlc ratio may be useful in patients with glycemic variations and the ratio was indeed higher in type $1 \mathrm{DM}$ (T1DM) patients (who are prone to show instable glycemic behaviors due to the lack of intrinsic insulin secretion) than those with type $2 \mathrm{DM}$ (T2DM) [2]. Establishing clinical indications for $\mathrm{GA} / \mathrm{HbAlc}$ ratio is necessary.

While abnormal erythrocyte conditions affect HbAlc measurement, GA can be influenced by abnormal albumin turnover conditions [3]. Further clarification of factors affecting GA is required to use the GA/HbAlc ratio appropriately. Men with normal glucose tolerance have been reported to have lower GA levels in smokers than nonsmokers [4]. Hence, we studied the association between the GA/HbAlc ratio and smoking among T1DM patients.

\section{KARGER \\ Fax +4161306 1234 \\ E-Mail karger@karger.ch}

www.karger.com
(C) 2010 S. Karger AG, Basel

1011-7571/10/0195-0415\$26.00/0

Accessible online at:

www.karger.com/mpp
Kazuhiko Kotani, MD, PhD

Department of Clinical Laboratory Medicine

Jichi Medical University, 3311-1 Yakushiji

Shimotsuke City, Tochigi 329-0498 (Japan)

Tel. +81 285587 386, Fax +81 285449 947, E-Mail kazukotani@jichi.ac.jp 
Table 1. Patients' characteristics

\begin{tabular}{lccc}
\hline Variable & $\begin{array}{l}\text { Smokers } \\
(\mathrm{n}=27)\end{array}$ & $\begin{array}{l}\text { Nonsmokers } \\
(\mathrm{n}=54)\end{array}$ & $\begin{array}{l}\text { All } \\
(\mathrm{n}=81)\end{array}$ \\
\hline Age, years & $45 \pm 13$ & $49 \pm 20$ & $48 \pm 18(20-85)$ \\
Men & $16(59 \%)$ & $16(30 \%)^{*}$ & $32(40 \%)$ \\
BMI, kg/m ${ }^{2}$ & $23.0 \pm 2.2$ & $22.0 \pm 2.7$ & $22.3 \pm 2.6(16.5-28.0)$ \\
Fasting plasma glucose, $\mathrm{mmol} / \mathrm{l}$ & $8.3 \pm 2.3$ & $8.9 \pm 3.1$ & $8.7 \pm 2.9(4.2-16.0)$ \\
GA, \% & $22.9(19.9-24.7)$ & $24.2(20.9-27.7)$ & $23.3(20.5-26.5)$ \\
HbA1c, \% & $7.4(6.4-8.1)$ & $7.5(6.5-8.3)$ & $7.4(6.5-8.3)$ \\
GA/HbAlc ratio & $3.0 \pm 0.2$ & $3.3 \pm 0.5^{*}$ & $3.2 \pm 0.4(2.4-4.4)$ \\
\hline \multirow{2}{*}{${ }^{*} \mathrm{p}<0.05}$. & & & \\
\hline
\end{tabular}

\section{Subjects and Methods}

We studied 81 cardiovascular disease-free T1DM patients (49 females, 32 males, mean age $48 \pm 18$ years). Eligibility criteria included absence of the acute phase of ketosis and hypoglycemia, use of insulin only therapy, and absence of conditions affecting albumin/erythrocyte turnover of severe liver disease, renal disorder, thyroid disease, anemia, malnutrition, malignancy, pregnancy and steroid therapy. In addition to body mass index (BMI) and fasting plasma glucose, GA and HbAlc were measured using an enzymatic method (Asahi Kasei Pharma, Tokyo, Japan) and a HPLC method, respectively. Smoking habits were confirmed via self-reports. The study was approved by the Institutional Review Board for Human Investigation.

Data were compared between smokers and nonsmokers using Student's t test, Mann-Whitney test or $\chi^{2}$ test. Data were presented as the mean $\pm \mathrm{SD}$, median (interquartile range) for nonparametric variables, GA and HbAlc or number (percentage) of subjects. In confounders-adjusted comparisons, a general linear model was used. $\mathrm{p}<0.05$ was considered significant.

\section{Results}

The patients' data are listed in table 1. Nonsignificant differences were seen in the levels of GA and HbAlc alone between smokers and nonsmokers. However, smokers had significantly lower levels of the GA/HbAlc ratio than nonsmokers. This difference remained unchanged after adjusting for age and sex $(\mathrm{p}=0.033)$ as well as age, sex and BMI $(\mathrm{p}=0.046)$.

\section{Discussion}

Smoking habits may affect the GA/HbAlc ratio in T1DM patients, in whom the evaluation of delicate glycemic trends by markers such as $\mathrm{GA} / \mathrm{HbAlc}$ ratio is often needed. This finding is noteworthy in regard to clinical application of this index.

There are several possible mechanisms for the smoking effect on the GA/HbA1c ratio in T1DM. General consensus has not necessarily been reached on the notion that smoking itself can directly worsen glycemic control, although the descriptions regarding their significant association exist [4]. Additionally, low GA in smokers has been demonstrated to be independent of glucose tolerance [4]. In our study, smoking did not statistically significantly affect fasting plasma glucose, GA and HbAlc levels. Even if smoking could worsen glycemic control, the contribution of smoking to glycemic control might not largely occur in T1DM where glycemic control often remains difficult to achieve under insulin therapy. Another considered fact is that habitual smoking leads to chronic inflammation and obesity (central obesity in particular) [5]. Whereas chronic inflammation may promote worsening glycemic control by HbAlc [6], it facilitates albumin turnover, leading to lower GA $[4,7]$. Although obesity promotes worsening glycemic control by HbAlc, it also increases albumin turnover $[3,7]$. Even though BMI does not always reflect central adiposity, BMI was actually reported to inversely correlate with $\mathrm{GA} / \mathrm{HbAlc}$ ratio $[1,3]$, due to the effects of obesity itself and/or obesity-induced chronic inflammation on albu$\min [3,7]$. There was a nonsignificant difference in BMI between smokers and nonsmokers among our subjects, and the difference in $\mathrm{GA} / \mathrm{HbAlc}$ ratio between smokers and nonsmokers was independent of BMI. The mean BMI of this population was under 30 with a fairly narrow range, and the independency of BMI seemed partly due to the nature of T1DM in which obesity/insulin resistance is not necessarily a primary characteristic in contrast to T2DM. This speculation is consistent with a prior 
report [2]. It is likely that smoking-induced chronic inflammatory reactions are more important than obesityrelated mechanism in lowering GA/HbAlc ratio among smokers with T1DM.

\section{Conclusion}

Our data show that smoking may affect GA/HbAlc ratio more than GA and HbAlc as independent factors.

\section{References}

-1 Takahashi S, Uchino H, Shimizu T, Kanazawa A, Tamura Y, Sakai K, Watada H, Hirose T, Kawamori R, Tanaka Y: Comparison of glycated albumin (GA) and glycated hemoglobin (HbAlc) in type 2 diabetic patients. Endocr J 2007;54:139-144.

-2 Yoshiuchi K, Matsuhisa M, Katakami N, Nakatani Y, Sakamoto K, Matsuoka T, Umayahara Y, Kosugi K, Kaneto H, Yamasaki Y, Hori M: Glycated albumin is a better indicator for glucose excursion than glycated hemoglobin in type 1 and type 2 diabetes. Endocr J 2008;55:503-507.
-3 Koga M, Matsumoto S, Saito H, Kasayama S: Body mass index negatively influences glycated albumin, but not glycated hemoglobin, in diabetic patients. Endocr J 2006;53:387391.

4 Koga M, Saito H, Mukai M, Otsuki M, Kasayama S: Serum glycated albumin levels are influenced by smoking status, independent of plasma glucose levels. Acta Diabetol 2009; 46:141-144.

5 Chiolero A, Faeh D, Paccaud F, Cornuz J: Consequences of smoking for body weight, body fat distribution, and insulin resistance. Am J Clin Nutr 2008;87:801-809.
-6 King DE, Mainous AG 3rd, Buchanan TA, Pearson WS: C-reactive protein and glycemic control in adults with diabetes. Diabetes Care 2003;26:1535-1539.

7 Koga M, Otsuki M, Matsumoto S, Saito H, Mukai M, Kasayama S: Negative association of obesity and its related chronic inflammation with serum glycated albumin but not glycated hemoglobin levels. Clin Chim Acta 2007;378:48-52. 